Pak. j. sci. ind. res. Ser. A: phys. sci. 2018 61A(3) 145-148

\title{
Extraction of Gold From Boulangrite Ore by Ammonium Thiocyanate $\left(\mathrm{NH}_{4} \mathrm{SCN}\right)$
}

\author{
Sajad Ali*, Sami Ullah, Muhammad Haris and Yaseen Iqbal \\ Materials Research Laboratory, Department of Physics, University of Peshawar, Peshawar-25120, Pakistan \\ (received January 1, 2018; revised April 9, 2018; accepted May 22, 2018)
}

\begin{abstract}
In this study extraction of gold from Boulangerite ore $\left(\mathrm{Pb}_{5} \mathrm{Sb}_{4} \mathrm{~S}_{11}\right)$ via ahydrometallurgical leaching process was studied. Boulangerite ore sample was collected from Shishy Valley, Chitral, Khyber Pakhtunkhwa, Pakistan. The Influence of various parameters on the extraction of gold from boulangerite ore was investigated i.e., the amount of ammonium thiocyanate, leaching time, particle size of ore and temperature. Ore with particle size in the range 100-300 mesh gave satisfactory yield values. An increase in amount of ammonium thiocyanate and boulangerite ore, leaching time and particle size resulted in an increase in the amount of leached gold. At optimal conditions the extraction of gold was observed to increase from $32 \%$ to $80.69 \%$.
\end{abstract}

Keywords: boulangerite ore, gold leaching, ammonium thiocyanate

\section{Introduction}

The demand for gold is constantly increasing due to its widespread use in electronic devices, jewellery and as economy. Consequently, its recovery from the relevant ores has become more important over the last few decades. Solvent extraction of gold from leach liquors has been studied extensively using ion pair or solvent extractants e.g., dibutylcarbitol (diethyleneglycoldibutyl ether), 4-methyl-2-pentanone (methyl isobutyl ketone; MIBK) and di (2-ethylhexyl) phosphoric acid (Akita et al., 1996). Solvent extraction has been used for the recovery of metals by means of hydrometal-lurgical process but this method is not used commercially for the purification and concentration of gold (Caravaca et al., 1996).Gold can be absorbed and eluted effectively using either strong or weak base anion exchange resins. Loading strong base resins with gold cyanide is an ion exchange mechanism involving the exchange of resin anions. Weak base resins typically have about one-half of the loading capacity than the strong base resins, but it needs an increase in the $\mathrm{pH}$ of the solution (Hariss et al., 1992).Using a mixture of amines and neutral organophosphorus derivatives has also been reported e.g., gold (I) has been extracted using primene $81 \mathrm{R}$ in cyanide media (Caravaca, 1994).

Cyanidation is an important process for extraction of gold from its ore. Gold cyanide complexes are formed as a result of gold dissolution in aerated cyanide solution. A large proportion of gold can be recovered from

*Author for correspondence; E-mail: sajjad2485@yahoo.com sulphide ores that are soluble in cyanide solution (Jeffrey and Breuer, 2000). However, a series of environmental accidents at various gold mines around the world has received widespread concern over the use of cyanide as a leaching reagent. In majority of these cases, cyanide from processing operations entered the environment either by leakage through tears and/or punctures in protective heap leach liners, or by spillage from over flowing solution ponds or tailings storage areas (Hilson and Monhemius, 2006).For this reason, gold leaching by cyanidation has been banned in many regions of the world in recent years. Also a cyanidation process usually takes more than $24 \mathrm{~h}$. Therefore, a slow gold leaching is often a problem of cyanidation process. In summary, high toxicity of cyanide,slow leaching kinetics and low gold extraction from refractory ores constitute the main problems of cyanide leaching (Orgul and Atalay, 2002).

Thiourea leaching is the most suitable alternative for cyanidation. The main difference between them is the use of different extracting agents. A large proportion of anionic thiourea is converted into formamidine disulphide (FDS) with the help of an oxidizing agent, which reacts with gold in an excessive thiourea medium. In order to minimize thiourea consumption, the solution $\mathrm{pH}$ and potential values $(\mathrm{mV})$ must be controlled (Gonen, 2003). Another non-cyanide leaching reagent thiosulphate has received much attention in recent years. Ammonium thiosulphate is an inexpensive nontoxic reagent. Acceptable leaching rates have been achieved using thiosulphate in the presence of ammonia with cupric ion acting as the oxidant. For example a total of 
1. 24 million tonnes low-grade refractory gold ore has been processed with ammonium thiosulphate at Newmont's operation near Carlin, Nevada, USA (Wan and Levier, 2003).

It was found that thiocyanate was an environment friendly reagent for gold leaching and more stable than thiourea in acidic solution. It was preferred to be used under weakly acidic conditions with a $\mathrm{pH}$ of 1.0 to 2.0 (Kholmogorov et al.,2002). Additionally,ammonium thiocyanate was cheaper than thiourea, sodium cyanide in commerce. However, gold leaching with thiocyanate was slower than with cyanide ( $\mathrm{Li}, 2012)$. Based on these previous studies, a low toxicity and lowcorrosiveness solution of ammoniumthiocyanate was thus used in the current work as lixiviant to extract gold from boulangerite ores.

\section{Materials and Methods}

Boulangerite $\left(\mathrm{Pb}_{5} \mathrm{Sb}_{4} \mathrm{~S}_{11}\right)$ ore was collected from Shishy Valley, Chitral $\left(35.84^{\circ} \mathrm{N}: 71.78^{\circ} \mathrm{E}\right)$, Khyber Pakhtunkhwa, Pakistan. Semi-quantitative EDS detected the presence of $52.43 \mathrm{wt} \% \mathrm{~Pb}, 24.85 \mathrm{wt} \% \mathrm{Sb}, 19.76 \mathrm{wt} \% \mathrm{~S}, 1.51$ wt $\% \mathrm{Cu}$ and traces of $\mathrm{Au}(15 \mathrm{ppm})$ in as-mined boulangerite ore sieved through a 200 mesh at Materials Research Laboratory (MRL), University of Peshawar.

The leaching experiments were carried out in a fume hood (LFH-120 SCI, LabTech). $3.0 \mathrm{~g}$ of weighed dried sample was placed in a $500 \mathrm{~mL}$ glass beaker. A deionized water of $20 \mathrm{~mL}$ with a pH of 1.5 adjusted using $2.5 \mathrm{M}$ $\mathrm{H}_{2} \mathrm{SO}_{4}$ was then put in the flask. After that $2.0 \mathrm{~g}$ of thiourea,were added to the flask, unless specified otherwise. The mixture solution was stirred at temperature of $60{ }^{\circ} \mathrm{C}$ at a speed of $300 \mathrm{rpm}$ by an electromagnetic stirrer with a Teflon coated stirring bar and a LED indicator showing the stirring speed.Aqueous samples were prepared in order to investigate the effect of various parameters i.e., leaching time, particle mesh size of the ore, amount of ammonium thiocyanate and amount of boulangerite ore. All the samples were analyzed for gold content using anatomic absorption spectrometer (AAS 700, Perkin Elmer, USA) in Centralized Resource Laboratory (CRL), University of Peshawar, Pakistan.

The percentage of gold extraction was calculated according to the following equation.

$$
\text { Au extraction }(\%)=\frac{[\mathrm{Au}] \times \mathrm{V}}{\mathrm{W}_{\mathrm{Au}}} \times 10^{2}
$$

where:

$\mathrm{W}_{\mathrm{Au}}$ is the weight of gold in milligram in the as- $\operatorname{mined}_{\mathrm{Au}}$ sample: $[\mathrm{Au}]$ is the concentration of gold from the filtrate in $\mathrm{mg} / \mathrm{L}$; $\mathrm{V}$ is the volume of filtrate in liter.

\section{Results and Discussion}

Effect of leaching time on the extraction of gold. Figure 1 shows the observed variation in the amount of gold at 200 mesh particle size as a function of leaching time.

The experimental results demonstrated that the extraction of gold increased from 33 to $36 \%$ by increasing leaching time from $1-3 \mathrm{~h}$; therefore, in the present study, maximum gold extraction was observed for $3 \mathrm{~h}$ leaching duration. Table 1 shows various parameters set for gold extraction in the present study.

The observed increase in the amount of extracted gold with time may be due to the relatively more mass loss (gangue) of the sample.

The effect of particle size of boulangerite ore on $\mathrm{Au}$ extraction. Figure 2 shows the observed variation in amount of extracted $\mathrm{Au}$ as a function of particle size of the boulangerite ore. It was observed that the amount of Au extracted increased from 32 to $38 \%$ with a decrease in the particle size of the ore from 100 mesh $(149 \mu \mathrm{m})$ to 300 mesh $(44 \mu \mathrm{m})$.

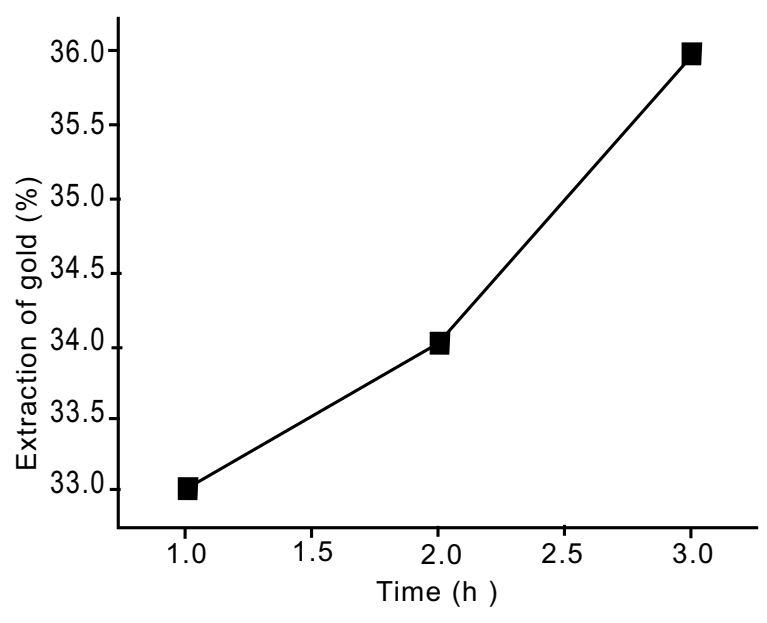

Fig. 1. Variation in the amount of extracted gold $_{\mathrm{Au}}$ from boulangerite ore as a function of leaching time (Experimental parameters: $60{ }^{\circ} \mathrm{C}, 300 \mathrm{rpm}$, ammonium thiocyanate $2 \mathrm{~g}$, boulangerite ore $3 \mathrm{~g}$, distilled water 20 $\mathrm{mL}$ ). 


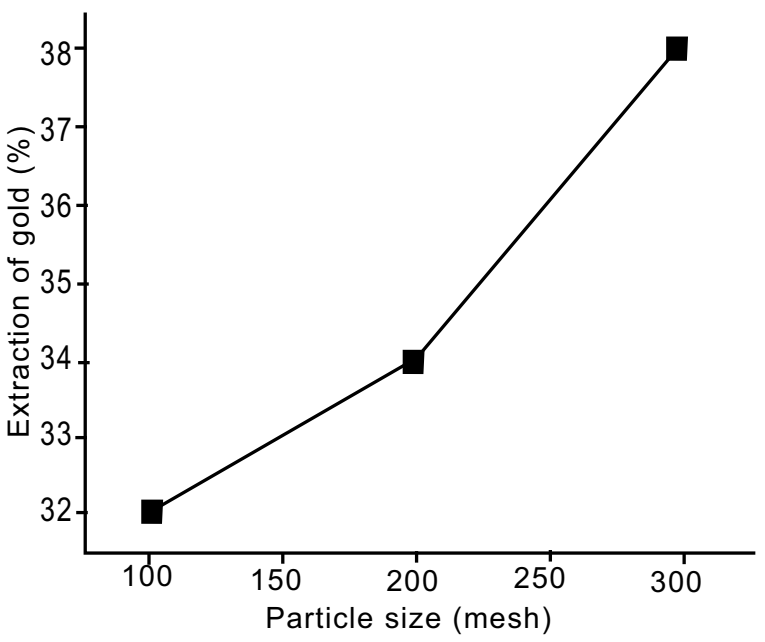

Fig. 2. The observed variation in the amount of extracted $\mathrm{Au}$ as a function of particle/mesh size of the boulangerite ore (Experimental conditions: $60{ }^{\circ} \mathrm{C} ; 3 \mathrm{~h} ; 300 \mathrm{rpm} ; 2 \mathrm{~g}$ ammonium thiocyanate, $3 \mathrm{~g}$ boulangerite ore, $20 \mathrm{~mL}$ distilled water).

The observed increase in the amount of extracted $\mathrm{Au}$ may be due to the diffusion of particles which allows relatively more thiourea to interact with Au particles leading to more leaching and hence, an increase in $\mathrm{Au}$ concentration.

Effect of ammonium thiocyanate amount. Figure 3 shows the observed variation in the amount of extracted $\mathrm{Au}$ from boulangerite ore as a function of ammonium thiocyanate content. Au extraction was observed to increase from $32 \%$ to $51 \%$ as a result of increasing ammonium thiocyanate amount from 3-6 g. The observed increase may be due to preferential adsorption of the ammonium thiocyanate onto the gold with increase in thiocyanate content.

Effect of boulangrite ore $\left(\mathrm{PB}_{5} \mathrm{SB}_{4} \mathrm{~S}_{11}\right)$ amount. Figure 4 shows the effect of ore amount on the extraction of gold from boulangerite ore and it dispatch that the amount of extracted $\mathrm{Au}$ increased from $32-40 \%$ with an increase in the amount of ore from $3-7 \mathrm{~g}$.

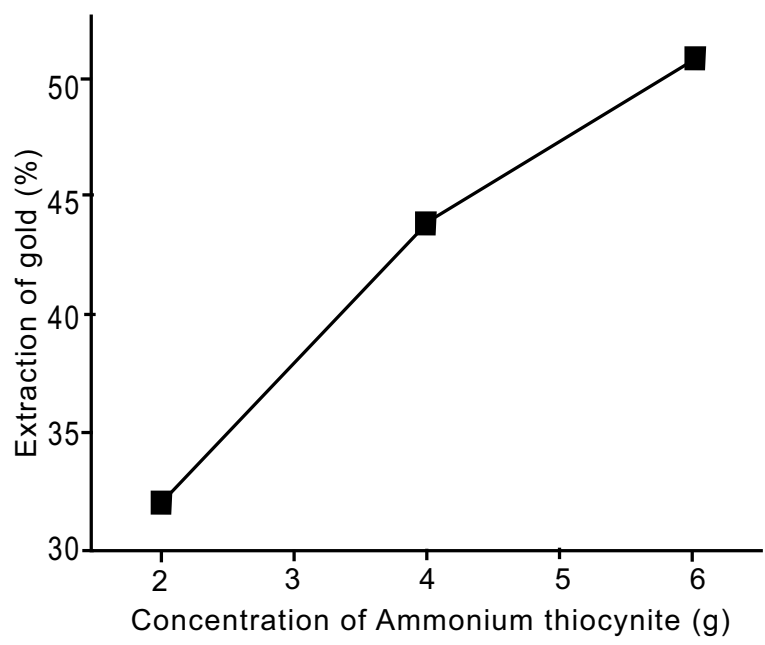

Fig. 3. The observed variation in the amount of extracted $\mathrm{Au}$ as a function of ammonium thiocyanate content (condition: $60{ }^{\circ} \mathrm{C} ; 3$ h; $300 \mathrm{rpm} ; 300$ mesh; boulangerite ore $3 \mathrm{~g}$; distilled water $20 \mathrm{~mL}$ ).

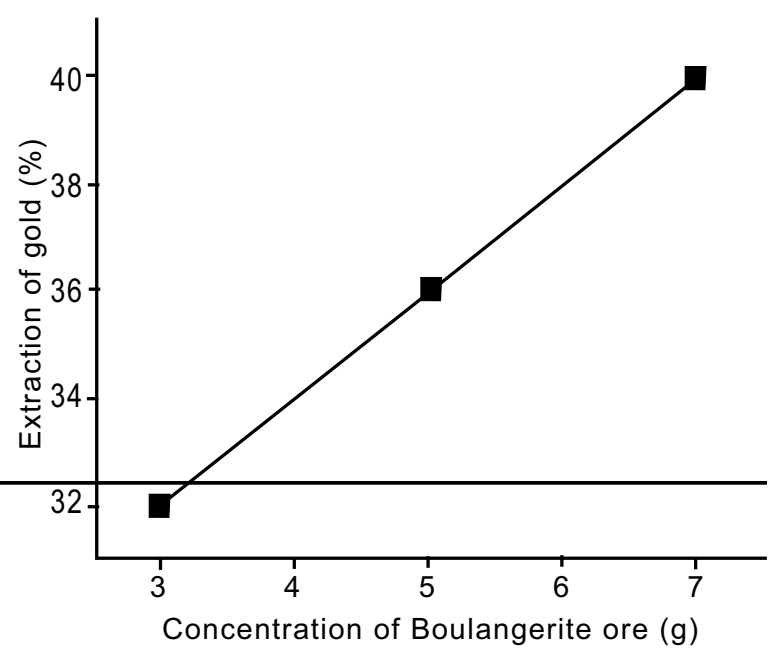

Fig. 4. The observed variation in the amount of extracted $\mathrm{Au}$ as a function of the amount of boulangerite ore (Experimental conditions: $60^{\circ} \mathrm{C} ; 3 \mathrm{~h}$; $300 \mathrm{rpm} ; 300$ mesh; ammonium thiocyanate $2 \mathrm{~g}$; distilled water $20 \mathrm{~mL})$.

Table 1. Quantitative data regarding the extraction of Au under the optimum conditions established in the present study

\begin{tabular}{lllllllll}
\hline \hline $\begin{array}{l}\text { Boulangerite } \\
\text { ore }(\mathrm{g})\end{array}$ & $\begin{array}{l}\text { Ammonium } \\
\text { thiocyanate } \\
(\mathrm{g})\end{array}$ & $\begin{array}{l}\text { Distill } \\
\text { water } \\
(\mathrm{mL})\end{array}$ & $\begin{array}{l}\text { Temp } \\
\left({ }^{\circ} \mathrm{C}\right)\end{array}$ & RPM & $\begin{array}{l}\text { Particle } \\
\text { size } \\
(\mathrm{mesh})\end{array}$ & $\begin{array}{l}\text { Time } \\
(\mathrm{h})\end{array}$ & $\begin{array}{l}\text { Filtrate } \\
\text { amount } \\
(\mathrm{mL})\end{array}$ & $\begin{array}{l}\text { Au } \\
\text { extraction } \\
(\%)\end{array}$ \\
\hline 7 & 6 & 30 & 60 & 300 & 300 & 3 & 25 & 80.69 \\
\hline \hline
\end{tabular}


Bulk production of the concentrate. The results of the experiment conducted under the optimum conditions established in the present study (i.e. $60{ }^{\circ} \mathrm{C}$ leaching temperature, $3 \mathrm{~h}$ leaching time, $300 \mathrm{rpm}, 300 \mathrm{mesh}$, $6 \mathrm{~g}$ ammonium thiocyanate, $7 \mathrm{~g}$ boulangerite ore) for leaching of $\mathrm{Au}$ are summarized in Table 1. These parameters enabled the extraction of $80.69 \%$ of $\mathrm{Au}$ from boulangerite ore.

\section{Conclusion}

This study demonstrated the suitability of the ammonium thiocyanate process for the gold recovery from boulangerite ore (Chitral) at laboratory scale. The effect of various factors on the extraction of $\mathrm{Au}$ from examined boulangerite ore containing $52.43 \mathrm{wt} \% \mathrm{~Pb}$, $24.85 \mathrm{wt} \% \mathrm{Sb}, 19.76 \mathrm{wt} \% \mathrm{~S}, 1.51 \mathrm{wt} \% \mathrm{Cu}$ and 1.45 wt $\%$ traces of Au (15 ppm) was investigated. The present experimental results demonstrated that the extraction of Au mainly depended on the concentration of free ammonium thiocyanate available for leaching i.e. higher Au extraction was achieved by increasing the amount of ammonium thiocyanate. Similarly the extraction of $\mathrm{Au}$ also increased with an increase in leaching time, particle size of the ore and the amount of boulangerite ore used. Employing the optimum experimental conditions established in the present study, the amount of extracted Au was $80.69 \%$. Thus ammonium thiocyanate can be commercially used for $\mathrm{Au}$ extraction from boulangerite ore.

\section{Acknowledgement}

The authors acknowledge the financial support of Higher Education Commission, Pakistan and the US National Academy of Science under the Pak-US joint S\&T Cooperation Programme for the project "Development of Materials Connection Center". The authors also acknowledge the financial support of the Khyber Pakhtunkhwa Government through the Pilot Research Studies Programme of the Directorate of Science \& Technology, KP for extension in the Mineral Up- gradation Pilot Plant and Up-gradation of Materials Research Laboratory, University of Peshawar, Pakistan.

\section{References}

Akita, S., Yang, L., Takeuchi, H. 1996. Solvent extraction of gold (III) from hydrochloric acid media by nonionic surfactants. Hydrometallurgy, 43: 37-46.

Caravaca,C., Alguacil,F. J., Sastre,A., Martinez,M. 1996. Extraction of gold (I) cyanide by the primary amine tridecylamine. Hydrometallurgy, 40: 89-97.

Caravaca, C. 1994. Gold (1) extraction equilibrium in cyanide media by the synergic mixture primene 81R-Cyanex 923. Hydrometallurgy, 35: 27-40.

Gonen, N. 2003. Leaching of finely disseminated gold ore with cyanide and thiourea solutions. Hydrometallurgy, 69: 169-176.

Hariss,W.I., Stahlbush, J.R., Pike, W.C., Stevens, R.R. 1992. The extraction of gold from cyanide solutions using moderate base polyamine ion exchange resins. Reactive Polymers, 17: 21-27.

Hilson, G., Monhemius, A.J. 2006. Alternatives to cyanide in the gold mining industry: what prospects for the future?. Journal of Cleaner Production, 14: 1158-1167.

Jeffrey, M.I., Breuer, P.L. 2000. The cyanide leaching of gold in solutions containing sulfide. Minerals Engineering, 13:1097-1106.

Kholmogorov, A.G., Kononova, O.N., Pashkov, G.L., Kononov, Y.S. 2002.Thiocyanate solutions in gold technology. Hydrometallurgy 64: 43-48.

Li, J. 2012. Thiocyanate hydrometallurgy for the recovery of gold. Part I: Chemical and thermodynamic considerations. Hydrometallurgy, 113-114- 1-9.

Örgül, S., Atalay, Ü. 2002.Reaction chemistry of gold leaching in thiourea solution for a Turkish gold ore. Hydrometallurgy, 67: 71-77.

Wan, R.Y., Levier, K.M. 2003. Solution chemistry factors for gold thiosulfate heap leaching. International Journal of Mineral Processing, 72: 311-322. 